\title{
Toss differences between the slice serve and the kick serve in tennis
}

\author{
Jan Carboch* and Vladimír Süss \\ Faculty of Physical Education and Sport, Charles University, Prague, Czech Republic
}

Copyright: (ㄷ 2015 J. Carboch and V. Süss. This is an open access article licensed under the Creative Commons Attribution License (http://creativecommons.org/licenses/by/4.0/).

\begin{abstract}
Background: Pre-contact information of servers' motion is important for receiving players in tennis. Objective: The aim of this study is to examine whether serving players use the same ball toss for kick serve (KS) and slice serve (SS) at two different directions of serves, from the receiver's view. Methods: 10 male right-handed professional tennis players with an average ATP ranking of 533 were videotaped from the receiver's view using a high-speed video camera $(200 \mathrm{~Hz})$. Firstly, they served SS and then KS from deuce court. After reaching 3 successful SS and $3 \mathrm{KS}$ to the correct location, the same procedure followed from the ad court. Kinematic analysis was used to obtain the point of ball release, vertical toss peak and racquet-ball contact. Results: Even though the release point was found nearly in the same location, the vertical toss peak of KS was horizontally to the right compared to SS and the point of racquet ball-contact of KS was even more to the right by approximately $30 \mathrm{~cm}$ from the receiver's view. Similar findings were obtained from deuce court and ad court. Conclusions: We found differences in the ball toss execution between KS and SS. The serve toss can provide useful information for receiving players. Serving players should use the same toss for each type of serve to hide their intention.
\end{abstract}

Keywords: anticipation, server, visual perception, receiver

\section{Introduction}

The tennis serve represents $45 \%$ (French Open) to $60 \%$ (Wimbledon) of the total number of strokes in a match (Johnson, McHugh, Wood, \& Kibler, 2006; O’Donoghue \& Ingram, 2001). Therefore, returning a tennis serve is very important. Even on the slowest court surface (clay courts), serves and returns are the strokes that influence match results the most in modern tennis (Gillet, Leroy, Thouvarecq, \& Stein, 2009). Tennis serves in professional tennis may reach a velocity higher than $200 \mathrm{~km} \cdot \mathrm{h}^{-1}$. Serve velocity decreases at the moment when a player makes a contact with the ball by $60-70 \%$ compared to its initial velocity (Coe, 2000). Dunlop (2000) and Kleinöder (2001) say, that the time of ball delivery is somewhere between 0.5-1.2 s, depending on serve quality (first and second serve), initial velocity and court surface. Crucial factors for a successful tennis return are timing and movement preparation, optimization of the initial position and reacting on velocity and direction of the moving

\footnotetext{
* Address for correspondence: Jan Carboch, Department of Sports Games, Faculty of Physical Education and Sport, Charles University, José Martího 31, 16200 Praha 6 - Veleslavín. E-mail: carboch@ftvs.cuni.cz
}

ball during the serve (Vaverka, Stromsik, \& Zhanel, 2003).

Previous pre-contact anticipation research (Day, 1980) showed that skilled tennis players were able to make predictions based on pre-contact cues. Williams, Davids, and Williams (1999) say that a player can rely on pre-contact cues more reliably compared to on-line visual information from early parts of a ball flight. Shim, Miller, and Lutz (2005) argue that it is possible to anticipate the type of stroke, but not the direction of the outgoing ball. Other studies (i.e. Abernethy \& Zawi, 2007; Shim, Carlton, \& Kwon, 2006) compared groups of novice players and expert players in a given sport. They show the different cues focusing between the groups and demonstrate higher fruitfulness of anticipation among experts. Goulet, Bard, and Fleury (1989) found that expert tennis players focus their vision more on the opponents' racquet-arm area whereas novice players focus on the ball. Shim et al. (2006) say that a relative racquet and forearm motion provides important information for opponent's perception as in this racquet and forearm motion there are differences in coordination patterns among different stroke types.

Players can use different types of tennis serve, e.g. flat serve, slice serve or kick serve. Players are using 
a sidespin when serving the slice serves. The sidespin causes the ball to curve from right to left in the air (from the view of right-handed server). For the kick serve, topspin is used. According to Cross (2011) when striking the ball for the kick serve sidespin is generated as well as topspin, meaning there is a spin axis on the ball and it is tilted away from vertical. Topspin forces the ball to sink down and bounce higher. Sakurai, Reid, and Elliot (2013) reported the kick serve had the highest ball spin rate, $3214 \mathrm{rpm}$ (revolutions per minute), while spin rate of the slice serve was only $2217 \mathrm{rpm}$. However the slice serve reached higher velocity than the kick serve. Cross (2011) argues the ball is served with about $4000 \mathrm{rpm}$ during the kick serve, but the spin is mostly sidespin and the amount of topspin is relatively small. As players are serving different types of the serves, different technique is required. When serving the kick serve, the racquet head strikes the ball in a direction that is partly sideways across the back of the ball (Cross, 2011). During final phases of the slice serve the racquet is approaching the impact point from the side and continues up over the ball (Crespo \& Miley, 1998). The sideways generates sidespin and the vertical component generates topspin.

In the case of right-handed players (server and receiver) and serving from the deuce court, the server usually serves the slice serve "wide" (the intersection of the service line and the sideline); and the kick serve to the "T location" (or $\mathrm{T}$ - junction of service line and center service line). However when serving from the ad court, the kick serves are usually aimed wide and the slice serve to T. Professional tennis players should use the same toss for each type of serve (Crespo \& Miley, 1998).

The aim of this study is to examine whether serving players use the same ball toss for kick serve (KS) and slice serve (SS) at two different directions of serves, from the receiver's view.

\section{Methods}

\section{Participants}

This study was performed with 10 male right-handed professional tennis players (age: $25.3 \pm 3.62$ years old; height: $184.9 \pm 6.28 \mathrm{~cm}$; weight: $81.6 \pm 9.81 \mathrm{~kg}$ ) with an average ATP ranking of 533 .

\section{Apparatus and procedures}

The research was carried out in an indoor tennis court. Players completed their regular match warm-up. They were instructed to serve the ball with maximum effort, exactly the same way they serve in a tennis match. The initial position of the server was the same for every trial. Firstly, they started to serve from the deuce court. There was a mark, which was $1 \mathrm{~m}$ to the right of the center service mark. For each trial, the server initiated his motion with touching the mark with the tip of his front foot. After hitting 3 successful KSs to T, they hit 3 successful SSs wide. Only successful serves were analyzed. The target areas were $3 \mathrm{~m}$ long and $1 \mathrm{~m}$ wide and reflected the landing location of two common serving locations ( $\mathrm{T}$ and wide). The action was recorded by a high-speed video camera (Basler piA640$210 \mathrm{gc}$, Basler, Ahrensburg, Germany) with a frequency of $200 \mathrm{~Hz}$. The high-speed video camera was placed in the position of receiving player, on the opposite court end of the server; $1 \mathrm{~m}$ behind the baseline, $0.5 \mathrm{~m}$ from the singles side line in the direction to the middle of the court and at the height of $1.6 \mathrm{~m}$, so that we could see the server's action (Figure 1). The serve speed was measured by radar (Stalker Pro II, Applied Concepts, Plano, TX, USA), which was placed next to the highspeed camera.

After finishing all the trials from the deuce court, the same procedure followed from the ad court. In this case, the KS was served wide and the SS to T. The initial position of the server, high-speed camera and radar position was exactly the same, but on the ad court (mirrored).

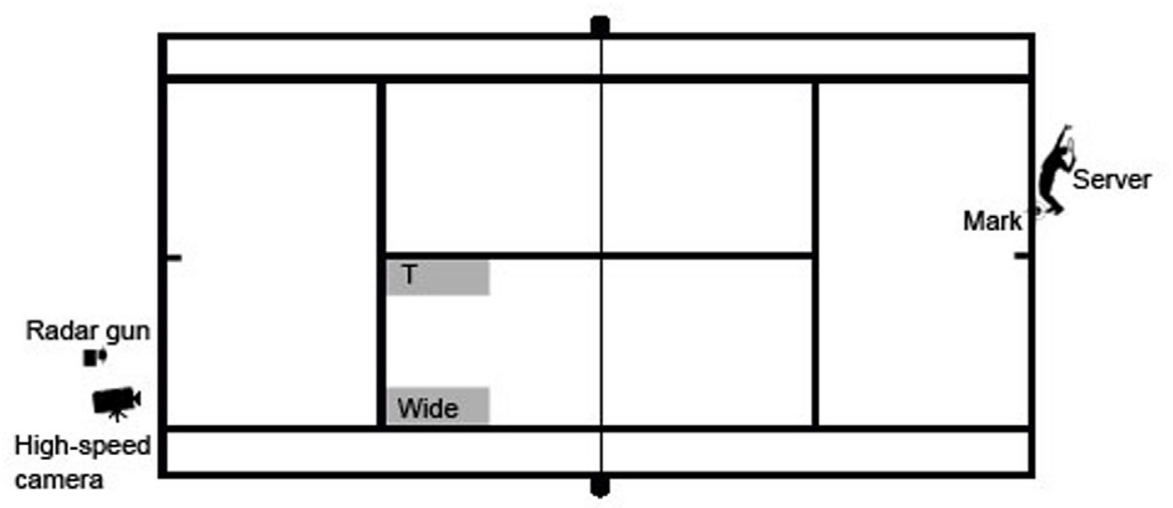

Figure 1. Deuce court experiment set up 


\section{Data analysis}

The research was evaluated from a two-dimensional analysis of the video recordings. The origin of global coordinate system was translated to the position of the front foot tip, which was determined prior to each participant's backswing, even though they initiated their motion every time from the same marked position, to ensure foot displacements (Figure 2). Two principal axes $\mathrm{X}$ and $\mathrm{Y}$ were used from the receiver's view. Positive $\mathrm{X}$ was horizontally to the right from the origin and positive Y was upward (vertical). Calibration procedure was done prior to each video recording. We used a calibration stick at the server's position (above the mark) to be able to determine the length parameters. Using software Dartfish 7 (Dartfish, Fribourg, Switzerland) we analyzed the ball location from all successful serves at: 1) ball release, 2) vertical toss peak, and 3) racquetball contact. Next, we analyzed the angle among the three mentioned points (i.e. the angle among the ball release, vertical toss peak and racquet-ball contact). Data evaluation was carried out using descriptive statistics and using paired-samples $t$-tests. The significance level was $\alpha=.05$.

\section{Results}

Altogether, 120 successful serves were analyzed. Results are split to receiving on deuce court and ad court, as the receiver can see the server from slightly different angle.

\section{Receiving on deuce court}

The ball release point was almost the same for both types of serves. However the vertical toss peak and

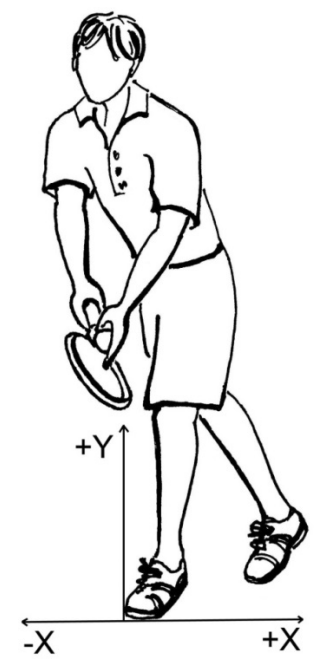

Figure 2. Orientation of global coordinate system racquet-ball contact was different, especially on the horizontal axis (see Table 1 for details). A paired-samples $t$-test was conducted to compare the ball toss kinematics. There was a significant difference in the scores of vertical toss peak on the horizontal $\mathrm{x}$-axis between $\mathrm{SS}$ and $\mathrm{KS} t(28)=-10.34, p<.001$. These results suggest that the vertical toss peak of KS was on the average $19.4 \mathrm{~cm}$ horizontally more to the right from the receiver's view. Another significant difference was reached in the scores at the racquet-ball contact on the horizontal X-axis between SS and KS $t(28)=-11.42$, $p<.001$. This means, when the players served the $\mathrm{KS}$, they contacted the ball on the average with their racquet $30.9 \mathrm{~cm}$ horizontally more to the right from the receiver's view. There was a significant difference in the scores at the point of the racquet-ball contact on the vertical $\mathrm{y}$-axis between SS and KS $t(28)=3.59$, $p=.001$. That means the ball during KS was contacted with the players' racquet an average of $5.7 \mathrm{~cm}$ lower.

A paired-samples $t$-test was conducted to compare the angle among the ball release point, the vertical toss peak and the racquet-ball contact of SS toss and KS toss. There was a significant difference in the scores between the toss of SS and KS $t(27)=-8.34, p<.001$. These results suggest that there is more acute angle in the SS toss.

Average SS speed was $167 \pm 7.7 \mathrm{~km} \cdot \mathrm{h}^{-1}$; and $\mathrm{KS}$ $141 \pm 8.1 \mathrm{~km} \cdot \mathrm{h}^{-1}$.

\section{Receiving on ad court}

Mean scores are shown in Table 2. A paired-samples t-test revealed there was a significant difference in the scores of vertical toss peak on the horizontal $\mathrm{X}$-axis between SS and KS $t(28)=-8.10, p<.001$. These results suggest that the vertical toss peak of KS was an average of $20.5 \mathrm{~cm}$ horizontally more to the right from the receiver's view. There was a significant difference in the scores at the racquet-ball contact on the horizontal $\mathrm{X}$-axis between SS and KS $t(28)=-8.89, p<.001$. This means, when the players served the KS, they contacted the ball with their racquet on the average $26.9 \mathrm{~cm}$ horizontally more to the right from the receiver's view.

A paired-samples $t$-test was conducted to compare the angle among the ball release point, the vertical toss peak and the racquet-ball contact of SS toss and KS toss. There was a significant difference in the scores between SS toss and KS $t(27)=-8.06, p<.001$. Similar to previous mentioned results (deuce court), these results also suggest that the ball toss trajectories of these types of serves are different as there is more acute angle at the SS toss from the receiver's view. Average SS reached $166 \pm 11.0 \mathrm{~km} \cdot \mathrm{h}^{-1}$; and $\mathrm{KS} 142 \pm 9.2 \mathrm{~km} \cdot \mathrm{h}^{-1}$. 


\section{Discussion}

During the tennis serve, it is the ball toss which potentially provides some cues for the receiver. We wanted to verify, if players use the same toss for different types of serve or not. Even though Crespo and Miley (1998) say the server should use the same toss for each type of serve, so that the receiver won't recognize (anticipate) the server's intention, we found players had used different ball tosses for KS and SS.

The horizontal component of the toss was different between SS and KS. The SS toss peak was more to the left from the receiver's view by about $19 \mathrm{~cm}$ (deuce court) or $16 \mathrm{~cm}$ respectively (ad court). Reid, Whiteside, and Elliot (2011) compared the ball toss for the first serve of professional tennis players served from deuce court to different locations (T, "body" and wide). He did not show such differences among the serve tosses as we did. Reid et al. (2011) showed maximum horizontal difference of $7 \mathrm{~cm}$ at the toss peak between the first serve to $\mathrm{T}$ and wide. The racquet-ball contact of SS was more to the left from the receiver's view by approximately $31 \mathrm{~cm}$ (deuce court) or $27 \mathrm{~cm}$ (ad court). This supports Abrams, Sheets, Andriacchi, and Safran (2011), because he reported KS to have a more medial (over the head), by nearly $20 \mathrm{~cm}$, contact point comparing to flat serve; and the contact point of slice serve was similar to the flat serve. Reid et al. (2011) argues the racquet-ball contact had maximum difference of $7 \mathrm{~cm}$ between the first serve to $\mathrm{T}$ and wide (deuce court). Also Chow et al. (2003) found

Table 1

Ball toss kinematics of slice serve and kick serve - deuce court

\begin{tabular}{|c|c|c|c|c|c|c|}
\hline & \multicolumn{2}{|c|}{ Slice serve } & \multicolumn{2}{|c|}{ Kick serve } & \multirow[b]{2}{*}{$t$} & \multirow[b]{2}{*}{$p$} \\
\hline & $M$ & $S D$ & $M$ & $S D$ & & \\
\hline \multicolumn{7}{|c|}{ Ball release $(\mathrm{cm})$} \\
\hline $\mathrm{X}$ & -12.3 & 10.3 & -11.6 & 9.9 & -0.32 & .750 \\
\hline $\mathrm{Y}$ & 182.2 & 13.0 & 181.7 & 12.3 & 0.47 & .646 \\
\hline \multicolumn{7}{|c|}{ Toss peak (cm) } \\
\hline$X$ & 9.3 & 12.6 & 28.7 & 11.3 & -10.34 & $<.001$ \\
\hline $\mathrm{Y}$ & 366.9 & 35.2 & 363.4 & 34.0 & 1.89 & .070 \\
\hline \multicolumn{7}{|c|}{ Racquet-contact $(\mathrm{cm})$} \\
\hline $\mathrm{X}$ & 18.3 & 15.1 & 49.2 & 17.8 & -11.42 & $<.001$ \\
\hline $\mathrm{Y}$ & 287.2 & 12.8 & 282.9 & 13.9 & 3.59 & .001 \\
\hline Angle $\left({ }^{\circ}\right)$ & 14.5 & 9.0 & 29.0 & 14.3 & -8.34 & $<.001$ \\
\hline
\end{tabular}

Note. $\mathrm{X}=$ horizontal axis, $\mathrm{Y}=$ vertical axis.

Table 2

Ball toss kinematics of slice serve and kick serve - ad court

\begin{tabular}{|c|c|c|c|c|c|c|}
\hline & \multicolumn{2}{|c|}{ Slice serve } & \multicolumn{2}{|c|}{ Kick serve } & \multirow[b]{2}{*}{$t$} & \multirow[b]{2}{*}{$p$} \\
\hline & $M$ & $S D$ & $M$ & $S D$ & & \\
\hline \multicolumn{7}{|c|}{ Ball release $(\mathrm{cm})$} \\
\hline $\mathrm{X}$ & -8.2 & 11.0 & -8.3 & 10.9 & 0.35 & .728 \\
\hline $\mathrm{Y}$ & 182.9 & 13.8 & 182.4 & 13.4 & 0.90 & .930 \\
\hline \multicolumn{7}{|c|}{ Toss peak $(\mathrm{cm})$} \\
\hline $\mathrm{X}$ & 17.2 & 12.7 & 33.7 & 11.7 & -8.10 & $<.001$ \\
\hline $\mathrm{Y}$ & 364.0 & 35.8 & 362.8 & 35.8 & 1.20 & .239 \\
\hline \multicolumn{7}{|c|}{ Racquet-contact $(\mathrm{cm})$} \\
\hline$X$ & 27.1 & 15.4 & 54.0 & 16.5 & -8.89 & $<.001$ \\
\hline $\mathrm{Y}$ & 284.8 & 10.5 & 282.7 & 11.6 & 2.03 & .051 \\
\hline Angle $\left({ }^{\circ}\right)$ & 16.7 & 9.5 & 30.5 & 13.66 & -8.06 & $<.001$ \\
\hline
\end{tabular}

Note. $\mathrm{X}=$ horizontal axis, $\mathrm{Y}=$ vertical axis. 
difference in horizontal toss displacement between the first serve and the second serve.

The vertical toss component was similar between SS and KS. Cross (2011) suggested increasing the height of ball toss would help to increase the amount of topspin because the racquet effectively approaches the ball at steeper angle when the vertical fall speed of the ball is increased. Contrary to this, our results showed players used the same toss height for both SS and KS. There was a tendency that players made the racquetball contact slightly lower when they served KS. Reid et al. (2011) did not find any differences in toss height nor the height of racquet-ball contact among first serves aimed to T, "body" or wide.

Sakurai et al. (2013) reported professional tennis players reached higher velocity in his study, when they served SS comparing to $\mathrm{KS}$. We can confirm this, because in our case SS was $25 \mathrm{~km} \cdot \mathrm{h}^{-1}$ faster than KS. Cross (2011) concluded to serve an efficient KS, the velocity of this serve should be at least $80 \mathrm{mph}$ $\left(129 \mathrm{~km} \cdot \mathrm{h}^{-1}\right)$. In our study the players reached average speed of KS $142 \mathrm{~km} \cdot \mathrm{h}^{-1}$ ( $88 \mathrm{mph}$ ) which shows us the tested players had a good quality of KS.

Although our study showed that players used different ball tosses between SS and KS, this study was limited having only two of the common serve types that were served to the different court locations. Future studies should also include the flat serve placed to different locations.

\section{Conclusions}

We found differences in the ball toss execution between KS and SS. Even though the ball release point is almost the same from the receiver's view, the racquet-ball contact point for $\mathrm{KS}$ serve is about $30 \mathrm{~cm}$ far to the right compared to SS. Therefore, the serve toss can provide useful information for receiving players as they can anticipate type of the serve from the server's toss before the ball is struck. Coaching instruction to serving players is to use the same toss for each type of serve to hide their intention.

\section{Acknowledgments}

The project was supported by PRVOUK P38.

\section{References}

Abernethy, B., \& Zawi, K. (2007). Pickup of kinematics underpins expert perception of movement patterns. Journal of Motor Behavior, 39, 353-357.
Abrams, G. D., Sheets, A. L., Andriacchi, T. P., \& Safran, M. R. (2011). Review of tennis serve motion analysis and the biomechanics of three serve types with implications for injury. Sport Biomechanics, 10, 378-390.

Chow, J. W., Carlton, L. G., Lim, Y., Chae, W., Shim, J., Kuenster, A. F., \& Kokubun, K. (2003). Comparing the pre and post-impact ball and racquet kinematics of elite tennis players' first and second serves: A preliminary study. Journal of Sports Sciences, 21, 529-537.

Coe, A. (2000). The balance between technology and tradition in tennis. In S. J. Haake \& A. Coe (Eds.), Tennis Science \& Technology (pp. 3-40). Oxford: Blackwell Science.

Crespo, M., \& Miley, D. (1998). Advanced coaches manual. London: International Tennis Federation.

Cross, R. (2011). The kick serve in tennis. Sports Technology, 4, 19-28.

Day, L. J. (1980). Anticipation in junior tennis players. In J. Groppel \& R. Sears (Eds.), Proceedings of International Symposium on Effective Teaching of Racquet Sports 1980 (pp. 107-116). Champaign, IL: University of Illinois.

Dunlop, J. I. (2000). Characterizing the service bouncing using a speed gun. In S. J. Haake \& A. Coe (Eds.), Tennis Science \& Technology (pp. 183-190). Oxford: Blackwell Science.

Gillet, E., Leroy, D., Thouvarecq, R., \& Stein, J. F. (2009). A notational analysis of elite tennis serve and serve-return strategies on slow surface. Journal of Strength and Conditioning Research, 23, 532-539.

Goulet, C., Bard, C., \& Fleury, M. (1989). Expertise differences in preparing to return a tennis serve: A visual information processing approach. Journal of Sport and Exercise Psychology, 11, 382-398.

Johnson, C. D., McHugh, M. P., Wood, T., \& Kibler, W. B. (2006). Performance demands of professional male tennis players. British Journal of Sports Medicine, 40, 696-699.

Kleinöder, H. (2001). The return of serve. ITF Coaching \& Sport Science Review, 24, 5-6.

O’Donoghue, P., \& Ingram, B. (2001). A notation analysis of elite tennis strategy. Journal of Sports Sciences, 19, 107-115.

Reid, M., Whiteside, D., \& Elliot, B. (2011). Serving to different locations: Set-up, toss, and racket kinematics of the professional tennis serve. Sports Biomechanics, 10, 407-414.

Sakurai, S., Reid, M., \& Elliot, B. (2013). Ball spin in tennis serve: Spin rate and axis of rotation. Sport Biomechanics, 12, 23-29.

Shim, J., Carlton, L. G., \& Kwon, Y. (2006). Perception of kinematic characteristics of tennis strokes for anticipating stroke type and direction. Research Quarterly for Exercise and Sport, 77, 326-339.

Shim, J., Miller, G., \& Lutz, R. (2005). Visual cues and information used to anticipate tennis ball shot and placement. Journal of Sport Behavior, 28, 186-200.

Vaverka, F., Stromsik, P., \& Zhanel, J. (2003). Player preparation for service return - a biomechanics viewpoint. In $\mathrm{S}$. Miller (Ed.), Tennis Science \& Technology 2 (pp. 193-198). London: International Tennis Federation.

Williams, A. M., Davids, K., \& Williams, J. G. (1999). Visual perception and action in sport. London: E \& FN Spon. 